\title{
De institutionele logica van de journalistiek: onderzoek naar het journalistieke veld in het spoor van Bourdieu
}

\begin{abstract}
Dit artikel gaat in op een aantal sleutelbegrippen uit Bourdieu's veldtheorie - de spanning tussen 'heteronomie' en 'autonomie', en de strijd tussen 'gevestigden' en 'nieuwkomers' - en hun belang voor de studie van de journalistiek. Beargumenteerd wordt dat de veldbenadering het gat kan dichten tussen analyses op het macroniveau, die journalistiek zien als het product van bredere maatschappelijke, economische en politieke structuren, en analyses op het microniveau, die geneigd zijn zich te richten op individuele nieuwsorganisaties en journalisten zonder veel aandacht te besteden aan de bredere institutionele setting waarin journalisten opereren. Bovendien wordt betoogd dat de veldbenadering een nuttig kader aanreikt voor internationaal vergelijkend onderzoek naar het functioneren van de journalistiek.
\end{abstract}

Inleiding

Binnen het veld van mediastudies is het werk van de Franse socioloog Pierre Bourdieu met de nodige reserve ontvangen. Na een aanvankelijk positief onthaal (Garnham \& Williams, I980), groeide de kritiek op de veronachtzaming van de media in Bourdieu's cultuurtheorie. De Engelse vertaling van Sur la télévision; suivi de l'emprise du journalisme (Bourdieu, I996/1998) bracht hier geen verandering in (Marlière, I998; Hesmondhalgh, 2006). Vooral Anglo-Amerikaanse mediawetenschappers bleken niet geporteerd van Bourdieu's bijdrage aan hun vakgebied, maar

\footnotetext{
Susanne Janssen is hoogleraar Media en Cultuur aan de afdeling Media en Communicatie van de Erasmus Universiteit Rotterdam. Haar onderzoek richt zich op de sociologie van cultuur, media en communicatie; en de sociologie van kunst en literatuur. Op dit moment werkt ze aan het onderzoeksproject Cultural Classification Systems in Transition waarvoor ze een Vici-subsidie ontving van NWO (Nederlandse Organisatie voor Wetenschappelijk Onderzoek). Correspondentieadres: Postbus I738, 3000 DR, Rotterdam, kamer L2-I6, tel: oIo-4082443, e-mail: s.janssen@uva.nl.
} 
ook hun collega's in andere landen (Bastin, 2003) wezen Bourdieu's polemische en populariserende analyse van de relatie tussen televisie en journalistiek als oppervlakkig van de hand. $\mathrm{Nu}$ viel en valt op deze analyse inderdaad veel af te dingen, maar dat geldt in mindere mate voor andere onderdelen uit Bourdieu's oeuvre. Diverse onderzoekers, waaronder de auteur van dit artikel, beschouwen Bourdieu's analyse van de werking van culturele productievelden (Bourdieu, I993, I996) als een nuttig en prikkelend denkkader voor de bestudering van media en journalistiek. Ook in internationaal vergelijkend journalistiekonderzoek heeft de veldbenadering inmiddels zijn vruchten afgeworpen.

Zo baseerden Daniel Hallin en Paolo Mancini zich voor hun invloedrijke, vergelijkende analyse van westerse mediasystemen op Bourdieu's veldtheorie, die zij in veel opzichten beter toepasbaar achtten dan op Durkheimiaanse leest geschoeide differentiatie- of systeemtheoretische benaderingen (Hallin \& Mancini, 2004). In Engeland hebben onder anderen Nick Couldry (2003), David Hesmondhalgh (2006) en Keith Negus (2006) de aandacht gevestigd op de bruikbaarheid van Bourdieu's ideeën voor onderzoek naar de wording en werking van media. Volgens een aantal Duitse auteurs kan Bourdieu's veldtheorie bijdragen aan het overbruggen van de aloude tegenstelling tussen 'structuur' en 'agency' binnen het journalistiekonderzoek (Hanitzsch, 2007; Meyen, 2009; Raabe, 2005; Schafer, 2004; Willems, 2007). In Nederland hebben met name onderzoekers op het gebied van de kunst- en cultuurjournalistiek zich laten inspireren door Bourdieu's werk (cf. Dorleijn \& Van Rees; Berkers et al, 20I0; Verboord, 2009; Van Venrooij, 2009). In Frankrijk verrichtten leerlingen van Bourdieu in de afgelopen twintig jaar een serie studies naar het Franse journalistieke veld. Zo onderzocht Patrick Champagne de relatie tussen journalistiek, politiek en publieke opinie (Champagne, I990), en de Franse berichtgeving over sociale malaise en stedelijke rellen (Champagne, 2000) en bloedschandalen (Champagne \& Marchetti, 2005). De neerslag van het Franse onderzoek naar het journalistieke veld is onder meer te vinden in twee speciale afleveringen van het door Bourdieu opgerichte tijdschrift Actes de la recherche en science sociales (Bourdieu et al, I994; Champagne et al, 2000) en de Engelstalige bundel Bourdieu and the Journalistic Field (Benson \& Neveu, 2005a). Buiten Frankrijk heeft Bourdieu vooral in de Amerikaanse socioloog Benson een belangrijke pleitbezorger gevonden (Benson 1999, 2004, 2005, 2006; Benson \& Neveu, 2005b).

Dit artikel beoogt enkele kernstukken uit Bourdieu's theorie van het culturele veld en hun mogelijke betekenis voor de studie van de journalistiek (opnieuw) onder de aandacht te brengen van onderzoekers in het Nederlandse taalgebied. Achtereenvolgens wordt ingegaan op het spanningsveld tussen 'heteronomie' en 'autonomie', de strijd tussen 'gevestigden' en 'nieuwkomers' en de brugfunctie die de veldbenadering kan vervullen tussen de macroanalyse op het niveau van de samenleving en haar economische en politieke structuren en de microanalyse op het niveau van individuele organisaties en journalisten. In het verlengde daarvan wordt betoogd dat 
de veldbenadering een bruikbaar kader biedt voor internationaal vergelijkend onderzoek naar het functioneren van de journalistiek.

\section{Autonomie én heteronomie}

Volgens Bourdieu en zijn volgelingen is het functioneren van een veld sterk afhankelijk van de plaats die het inneemt ten opzichte van andere velden. Het journalistieke veld situeren zij binnen het veld van de macht ('field of power'), als deel van het 'veld van culturele productie' (Bourdieu, I993) dat binnen het veld van de macht een ondergeschikte positie wordt toegedacht. Net als andere vormen van culturele productie, voltrekt de productie van nieuws zich deels binnen een 'relatief autonoom' veld van 'kleinschalige' productie en (groten)deels binnen een 'heteronoom' veld van grootschalige productie. Afgezet tegen sommige andere culturele productievelden is de autonomie van het journalistieke veld beperkt. Niettemin valt ook de journalistiek volgens Bourdieu het best te begrijpen als een veld dat functioneert volgens eigen wetten en regels.

In zijn denkkader draaien de sociale werkelijkheid als geheel en specifieke velden daarbinnen rond twee vormen van macht: economisch en cultureel 'kapitaal'. De specifieke verschijningsvorm van deze machtsbronnen verschilt per veld. Binnen het journalistieke veld valt economisch kapitaal af te lezen aan oplages, advertentieinkomsten en kijkcijfers, terwijl cultureel kapitaal geassocieerd is met prestigieuze journalistieke genres en vormen en uitdrukking vindt in de professionele erkenning van collega-journalisten. Elk veld is met andere woorden gestructureerd rond de tegenstelling tussen een 'heteronome' pool waar veldexterne (vooral economische) krachten domineren en een 'autonome' pool waar een veldspecifieke vorm van kapitaal (journalistieke excellentie/prestige) de boventoon voert. Sommige actoren binnen het journalistieke veld kunnen bogen op veel economisch kapitaal, anderen genieten een uitstekende journalistieke reputatie, weer anderen zijn op beide fronten succesvol of scoren juist laag over de hele linie.

Enerzijds onderscheidt de veldtheorie zich daarmee van traditionele politieke economiemodellen (Frankfurter Schule, Schiller, McChesney) en varianten daarop (Habermas' model van de publieke sfeer, Gamsci's hegemoniebenadering), die media primair beschouwen als economische en/of politieke machtsinstrumenten en de nadruk leggen op de ideologische bepaaldheid van media. Anderzijds onderscheidt de veldbenadering zich van veel etnografisch getint onderzoek naar nieuwsorganisaties en nieuwsproductie (cf. Cottle, 2007; Schultz, 2007) door systematisch aandacht te besteden aan de inbedding van media en journalistiek in bredere machtsystemen. 
'Media logic is political and economic; it is also professional' (Benson, 2006: 196). De kracht van de veldtheorie ligt in die gelijktijdige nadruk op het eigenstandige karakter van de journalistiek en haar verwevenheid met andere velden, het economische en politieke veld, maar ook met de velden van onderwijs en wetenschap (cf. Hesmondhalgh, 2006). In plaats van mediabedrijven en journalisten over één kam te scheren en hen a priori tot doorgeefluik dan wel criticaster van de economische of politieke macht te bombarderen, vestigt de veldtheorie de aandacht op de differentiatie binnen het journalistieke veld: tussen relatief autonome, kleinschalige vormen van journalistieke productie en het door heteronome (economische) principes gereguleerde veld van grootschalige nieuwsproductie. In welke mate en op welke wijze externe invloeden doorwerken in de productie van nieuws, is onder meer afhankelijk van de specifieke positie die actoren binnen het journalistieke veld innemen. Binnen het journalistieke veld is met andere woorden sprake van een 'refractie' en niet van een 'reflectie' van externe factoren.

\section{Oud versus nieuw}

Naast de tegenstelling tussen heteronomie en autonomie speelt ook de oppositie tussen 'gevestigden' en 'nieuwkomers' een centrale rol in het veldperspectief. Daarmee richt de veldbenadering de aandacht op de invloed van diverse, onderbelichte factoren op de journalistieke productie, zoals de dynamiek van de economische en professionele concurrentie tussen de diverse spelers binnen het journalistieke veld; de verhouding tussen het aantal aspirant-journalisten en de hoeveelheid beschikbare posities; veranderingen in de sociale achtergrondkenmerken van nieuwkomers in het veld; en de historische ontwikkelingsgang van het journalistieke veld.

Binnen elk veld speelt zich een strijd af tussen gevestigde actoren die hun macht proberen te continueren en nieuwe spelers die nog een plek moeten veroveren. Waar de gevestigde orde doorgaans geen belang heeft bij verandering, zijn nieuwkomers gebaat bij een verandering of omverwerping van de status quo. Zij proberen een positie te creëren door zich als 'vernieuwers' te profileren en zich aldus te onderscheiden van de gevestigde producenten. Deze distinctiedrift manifesteert zich in de vestiging van nieuwe bewegingen, stromingen en stijlen en daarmee verbonden publicatiekanalen die zich afzetten tegen de gangbare journalistieke codes en conventies (cf. bijv. Champagne \& Marchetti, 2005; Van Dijk \& Janssen, 200I). Neveu (2007) geeft in dit verband het voorbeeld van de Amerikaanse New Journalism-beweging, die het principe van journalistieke objectiviteit verwierp en pleitte voor de inzet van literaire stijlmiddelen in de journalistiek. Een voorbeeld dichter bij huis levert de Nederlandse website GeenStijl die met succes een positie in het Nederlandse journalistieke veld heeft opgeëist door gangbare journalistieke normen met voeten te treden. 
De onderscheidingsdrang van nieuwkomers vormt - samen met veranderingen in aanpalende velden als de politiek of het onderwijs - een belangrijke bron van verandering en vernieuwing in culturele productievelden. Ook de sociale achtergrond van nieuwkomers is relevant in dit kader. De kans op verandering neemt toe naarmate meer nieuwkomers een andere sociale achtergrond - en daarmee een andere 'habitus' - hebben dan de gevestigde actoren in het veld. In hoeverre dergelijke 'morfologische' veranderingen leiden tot een transformatie van journalistieke praktijken is tevens afhankelijk van bredere sociale, politieke, economische of technologische factoren en processen. Bovenstaande inzichten bieden in mijn optiek een goed aanknopingspunt om de positie en impact van bloggers en online nieuwsproducenten in het journalistieke veld te onderzoeken.

\section{Schakel tussen macro en micro}

De veldbenadering introduceert een nieuw analyseniveau voor de studie van de journalistiek, tussen de macroanalyse op het niveau van de samenleving en haar economische en politieke structuren en de microanalyse op het niveau van individuele organisaties en journalisten. Onderzoek op het mesoniveau van het journalistieke 'veld' bestudeert de wisselwerking tussen structurele factoren (bijv. wet- en regelgeving en de verhouding tussen publiek/privaat eigendom) en professionele en organisatorische factoren (professionele ideologie en rolopvattingen van journalisten, journalistieke praktijken en routines, relaties met officiële bronnen, enzovoort). Maar veldonderzoek analyseert ook de relaties en interacties tussen de diverse actoren binnen de journalistiek, de regels en principes die hun handelingen sturen en de historische formatie en ontwikkelingsgang van de journalistiek als een semiautonoom veld met een eigen institutionele logica. Daarmee vertoont de veldbenadering grote raakvlakken met een neo-institutionele analyse van media en journalistiek (Benson, 2006; Ryfe, 2006). Belangwekkender dan die overeenkomsten zijn de punten waarop beide benaderingen elkaar kunnen aanvullen en versterken. Zo zou de veldbenadering zijn voordeel kunnen doen met inzichten over de invloed van de staat zoals die binnen het neo-institutionalisme zijn ontwikkeld (Benson, 2006).

Volgens diverse critici verwaarloost Bourdieu de impact van politieke factoren op culturele productievelden en gooit hij politieke en economische invloeden op een, 'heteronome' hoop. Politieke en economische macht vallen echter lang niet altijd samen en kunnen zelfs op gespannen voet staan. Diverse internationaal vergelijkende studies (Hallin \& Mancini, 2004; Benson \& Hallin, 2007; Benson, 2009) tonen de complexiteit en de veelvormigheid van de betrekkingen tussen journalistiek, markt en staat en de effecten daarvan op de modus operandi van journalisten en de vorm en inhoud van nieuwsmedia. In veel landen wordt de werking van marktfactoren aan banden gelegd door geïnstitutionaliseerde vormen van overheidssteun gericht op de instandhouding van een politiek en financieel onafhankelijke 
journalistieke informatievoorziening. Zelfs in de Verenigde Staten, waar de overheid in beginsel zo min mogelijk interfereert in de markt, heeft het mediabeleid van de overheid een onuitwisbaar stempel gedrukt op het mediasysteem (Cook, I998).

De veldbenadering heeft ook het nodige te winnen bij een incorporatie van neoinstitutionele ideeën over de impact van organisatie-ecologische aspecten op de journalistieke productie, zoals de mate van centralisatie van mediaorganisaties en de intensiteit van de onderlinge competitie tussen nieuwsmedia. Distinctiedrang is weliswaar een vruchtbaar concept gebleken in onderzoek naar verandering en vernieuwing in culturele productievelden, maar het is minder bruikbaar in de verklaring van homogeniseringstendensen binnen de journalistiek en andere culturele productievelden. Hier zou de veldtheorie kunnen aanknopen bij neo-institutionele inzichten over 'isomorfie' (DiMaggio \& Powell, 1991: 67). Organisaties binnen een sector gaan vaak op elkaar lijken omdat ze te maken hebben met dezelfde omgevingsfactoren. Ze kopiëren en imiteren elkaar om onzekerheden te reduceren, onder druk van instanties van wie ze afhankelijk zijn, en door harmonisering van professionele normen en waarden (via opleidingsinstanties en beroepsorganisaties). Institutionele isomorfie draagt bij aan de legitimiteit van organisaties en bevordert hun overlevingskansen. De onstuitbare opmars van een objectieve, informerende stijl van berichtgeving in westerse nieuwsmedia gedurende de twintigste eeuw, maar ook de recente omarming van het tabloidformaat door een groeiend aantal Nederlandse en Europese (kwaliteits)kranten vallen goed in die termen te duiden.

\section{Internationaal vergelijkend onderzoek}

Het veldtheoretisch kader heeft in mijn ogen vooral veel te bieden in internationaal vergelijkend onderzoek naar de journalistiek. De impact van globalisering op nationale media en mediasystemen is een veelbesproken kwestie (Chadva \& Kavoori, 2005; Hallin \& Mancini, 2004; Hardy, 2008). Met de erosie van nationale grenzen en de rol van natiestaten zijn volgens globaliseringstheoretici nationale verschillen in politiek, economie, cultuur en media in hoog tempo aan het verdwijnen. De studie van nationale media en mediasystemen zou daarom plaats moeten maken voor een postnationale analyse. Onmiskenbaar is het volume en bereik van transnationale betrekkingen en uitwisselingen op alle gebieden in de afgelopen dertig jaar explosief gegroeid en ongetwijfeld heeft dit ook de productie van nieuws diepgaand beïnvloed. Maar de globaliseringliteratuur verschaft vooralsnog maar weinig empirische gegevens over de veranderingen die zich op journalistiek gebied hebben voorgedaan onder invloed van of in reactie op globalisering.

Vergelijkend onderzoek naar (de gevolgen van globalisering voor) de aard en werking van nationale mediasystemen en journalistieke velden kan de kloof dichten tussen traditionele studies van nationale media waarin de impact van globalisering- 
tendensen niet uit de verf komt en globaliseringtheorieën die onvoldoende oog hebben voor nog altijd bestaande nationale verschillen en de voortdurende invloed van nationale overheden en mediasystemen. De mediasystemen van westerse landen zijn weliswaar meer op elkaar gaan lijken sinds de jaren zeventig van de vorige eeuw, maar tegelijkertijd is sprake van allerlei uitzonderingen en tegenbewegingen waardoor die convergentietrend niet zonder meer valt door te trekken in de toekomst (Hallin \& Mancini, 2004; Hallin, 2009: 334)

Elvestad en Blekesaune (2008) onderzochten bijvoorbeeld het lezen van kranten binnen landen met verschillende mediasystemen. Niet alleen vonden zij aanzienlijke nationale variaties in de tijd die mensen besteedden aan het lezen van kranten, maar deze verschillen bleken bovendien voor een deel terug te voeren op nationale (veld)kenmerken waaronder het aanbod van lokale en regionale kranten en het aandeel van kranten in advertentie-uitgaven. Curran et al. (2009) vergeleken de kennis van het publiek over politiek en internationale ontwikkelingen voor vier landen met een verschillend mediasysteem. Zij constateerden dat het publieke omroepmodel de kennis van het publiek op deze gebieden vergroot, de consumptie van nieuws bevordert en bovendien de kenniskloof tussen rijk en arm reduceert.

Een andere vruchtbare lijn van crossnationaal onderzoek betreft de vraag hoe kenmerken van nationale mediasystemen en journalistieke velden doorwerken in de vorm en inhoud van nieuws. Meestal wordt aangenomen dat nieuwsmedia meer sensatie- en schandaalgericht zijn in een door de markt gedomineerd mediasysteem dan in een systeem waar de overheid kranten en andere media tot op zekere hoogte vrijwaart van commerciële invloeden. Maar de organisatie-ecologie van nationale journalistieke velden biedt misschien wel een betere verklaring voor de mate van sensationalisme en schandaalgerichtheid in de journalistieke berichtgeving (Benson \& Hallin, 2005; Esser, I999). Zo bleek het sterk gecentraliseerde en concurrerende Franse journalistieke veld in de laatste drie decennia van de vorige eeuw aanmerkelijk meer schandaalberichtgeving over immigratie te genereren dan het sterk markgerichte, maar meer gefragmenteerde Amerikaanse journalistieke veld (Benson \& Saguy, 2005). De invloed van veldkenmerken wordt bevestigd door studies naar de diversiteit van de berichtgeving over controversiële onderwerpen (Benson, 2009; Woods, 2007) en de journalistieke aandacht voor populaire cultuur in Amerikaanse en Europese kwaliteitskranten (Janssen, Verboord \& Kuipers, 20II).

Ook de vooralsnog schaarse crossnationale onderzoeken naar online nieuwsmedia onderstrepen de robuustheid van nationale verschillen en daarmee de noodzaak en meerwaarde van vergelijkend onderzoek naar de impact van veld- en systeemkenmerken op de journalistieke productie. Dergelijk onderzoek kan tevens blootleggen in hoeverre en op welke wijze journalistieke standaarden, praktijken en processen ingebed zijn geraakt in een 'transnationaal' veld (Bourdieu, 2000, 98; Shoemaker \& Vos, 2009, I33 e.v.) met een eigen institutionele logica. 


\section{Literatuur}

Bastin, G. (2003). Ein Objekt, das sich verweigert: Der Journalismus in der Soziologie Pierre Bourdieus. Einige Bemerkungen über das journalistische Feld'. Publizistik, 48, 258-273.

Benson, R. (I999). Field Theory in Comparative Context: A New Paradigm for Media Studies. Theory and Society, 28, 463-498.

Benson, R. (2004a). Bringing the Sociology of Media Back in. Political Communication, 21, 275-292.

Benson, R. (2004b).Why Conceptual Models and 'Big' Institutions Matter: A Response to David Altheide, Nina Eliasoph, William Gamson, and Todd Gitlin. Political Communication, 2I, 3II-3I4.

Benson, R. (2005). Mapping Field Variation: Journalism in France and the United States. In R. Benson \& E. Neveu (eds.), Bourdieu and the journalistic field (pp. 85-II2). Cambridge, UK: Polity Press.

Benson, R. (2006). News Media as a 'Journalistic Field': What Bourdieu Adds to New Institutionalism, and Vice Versa. Political Communication, 23, I87-202.

Benson, R. (2009). What makes news more multiperspectival? A field analysis. Poetics. Journal of Empirical Research on Culture, the Media and the Arts, 37, 402-418.

Benson, R. \& D.C. Hallin (2007). How States, Markets and Globalization Shape the News. The French and US National Press, I965-97. European Journal of Communication, 22, 27-49.

Benson, R. \& E. Neveu (red.) (2005a). Bourdieu and the Journalistic Field. Cambridge, UK: Polity Press.

Benson, R., \& Neveu, E. (2005b). Introduction: Field theory as a work in progress. In R. Benson \& E. Neveu (red.). Bourdieu and the journalistic field (pp. I-25). Cambridge, UK: Polity Press.

Benson, R., \& A.C. Saguy (2005). Constructing social problems in an age of globalization: A FrenchAmerican comparison. American Sociological Review, 70, 233-259.

Berkers, P., S. Janssen \& M. Verboord (20I0). Assimilatie in de literaire mainstream? Etnische grenzen in dagbladrecensies van etnische minderheidsauteurs in de Verenigde Staten, Nederland en Duitsland. Mens en Maatschappij, 85.

Bourdieu, P. (1993). The Field of Cultural Production. Cambridge: Polity Press.

Bourdieu, P. (1996/1992). The Rules of Art: Genesis and Structure of the Literary Field. Cambridge, UK: Polity press.

Bourdieu, P. (1998/1996). On Television. Cambridge, UK: Polity Press.

Bourdieu, P., et al. (I994). L'emprise de journalisme. Acte de recherche en sciences sociales Io/102.

Bourdieu, P. (2000). Pascalian Meditations, Palo Alto, CA: Stanford University Press.

Chadha, K. \& A. Kavoori. (2005). Globalization and National Media Systems: Mapping Interactions in Policies, Market and Formats. In J. Curran \& M. Gurevitsch (red.). Mass Media and Society. London: Arnold.

Champagne, P., et al. (2000). Le journalisme et l'économie. Actes de recherche en sciences sociales, I3//132.

Champagne, P. \& D. Marchetti (2005). The Contaminated Blood Scandal: Reframing Medical News. In R. Benson \& E. Neveu (eds), Bourdieu and the journalistic field (pp. II3-I35). Cambridge, UK: Polity Press.

Cook, T. E. (1998). Governing with the news: The news media as a political institution. Chicago: University of Chicago Press.

Cottle, S. (2007). Ethnography and News Production: New(s) Developments in the Field. Sociology Compass, I.

Couldry, N. (2003). Media Meta-capital: Extending the Range of Bourdieu's Field Theory. Theory and Society, 32, 653-77.

Curran, J., S. Iyengar, A. Brink \& I. Salovaara-Moring (2009). Media System, Public Knowledge and Democracy. A Comparative Study. European Journal of Communication 24 (I), 5-26.

Dijk, N. van \& S. Janssen (200I). De reuzen voorbij. De metamorfose van de literaire kritiek in de pers na I965. In J. Bardoel et al. (red.), Journalistieke cultuur in Nederland (pp. 208-235). Amsterdam: Amsterdam University Press.

Dorleijn, G.J. \& K. van Rees (red.) (2006). De productie van literatuur. Het literaire veld in Nederland 1800-2000. Nijmegen: Vantilt. 
Elvestad, E. \& A. Blekesaune (2008). Newspaper Readers in Europe. European Journal of Communication, $23,425-447$.

Esser, F. (I999). 'Tabloidization' of news: A comparative analysis of Anglo-American and German press journalism. European Journal of Communication, I4, 29I-324.

DiMaggio, P. J. \& W.W. Powell (red.) (I99I). The new institutionalism in organizational analysis. Chicago: University of Chicago Press.

Garnham, N. \& R. Williams (I980). Bourdieu and the Sociology of Culture. Media, Culture \& Society, 2, $209-223$.

Hallin, D. \& P. Mancini (2004). Comparing Media Systems. Three Models of Media and Politics. Cambridge, UK: Cambridge University Press.

Hallin, D. (2009). Not the end of journalism history. Journalism,Io, 332-334.

Hanitzsch, T. (2007). Die Struktur des journalistischen Feldes. In K.-D.Altmeppen, T. Hanitzsch \& C. Schlüter (red.), Journalismustheorie: Next Generation (pp. 239-260). Wiesbaden: Vs Verlag.

Hardy, J. (2008). Western Media Systems. Londen: Routledge.

Hesmondhalgh, D. (2006). Bourdieu, the Media and Cultural Production. Media, Culture and Society, 28, 2II-23I.

Janssen, S. , M. Verboord \& G. Kuipers. (20II). Comparing Cultural Classification. High and Popular Arts in European and U.S. Elite Newspapers. Kölner Zeitschrift für Soziologie und Sozialpsychologie, 63.

Marlière, P. (1998). The rules of the journalistic field: Pierre Bourdieu's contribution to the sociology of the media. European Journal of Communication, I3, 219-234.

Meyen, M. (2009). Das journalistische Feld in Deutschland. Ein theoretischer und empirischer Beitrag zur Journalismusforschung. Publizistik, 54, 323-345.

Negus, K. (2006). Rethinking Creative Production Away from the Cultural Industries. In J. Curran \& D. Morley (red.). Media and Cultural Theory (pp. I97-208). Abingdon: Routledge.

Neveu, E. (2007). Pierre Bourdieu: Sociologist of Media, or Sociologist for Media Scholars? Journalism Studies, 8, 335-47.

Raabe, J. (2005). Die Beobachtung journalistischer Akteure. Wiesbaden: Vs Verlag.

Ryfe, D.M. (2006). Guest Editor's Introduction: New Institutionalism and the News. Political Communication, 23, I35-I44.

Schäfer, S. (2004). Journalismus als soziales Feld. In M. Löffelholz (red.), Theorien des Journalismus. Ein diskursives Handbuch (pp. 32I-334). Wiesbaden: Vs Verlag.

Schultz, I. (2007). The Journalistic Gut Feeling. Journalism Practice I, I90-207.

Shoemaker, P.J. \& T.P. Vos (2009). Gatekeeping Theory. New York: Routledge.

Venrooij, A. van (2009). The aesthetic discourse space of popular music: 1985-86 and 2004-05. Poetics, $37,315-332$.

Verboord, M. (2009). Legitimacy of Book Critics in the Age of Internet and Omnivorousness. European Sociological Review. Advance Access published on August 3, 2009.

Willems, H. (2007). Elemente einer Journalismustheorie nach Bourdieu. In K.-D. Altmeppen, T. Hanitzsch, \& C. Schlüter (red.), Journalismustheorie: Next Generation (pp. 215-238). Wiesbaden: Vs Verlag.

Woods, J. (2007). Democracy and the press: A comparative analysis of pluralism in international print media. The Social Science Journal, 44, 213-230. 